OPEN ACCESS

Edited by:

Mayela Rodríguez-Violante, Manuel Velasco Suárez Instituto

Nacional de Neurología y Neurocirugía, Mexico

Reviewed by:

Fabiana Novellino,

National Research Council (CNR), Italy

Matteo Bologna,

Sapienza University of Rome, Italy

${ }^{*}$ Correspondence:

Tao Feng

bxbkyjs@sina.com

Specialty section: This article was submitted to

Movement Disorders,

a section of the journal

Frontiers in Neurology

Received: 12 July 2020 Accepted: 22 September 2020 Published: 29 October 2020

Citation:

Wang X, Cao Z, Liu G, Liu Z, Jiang Y, Ma $H$, Wang $Z$, Yang $Y$, Chen $H$ and Feng T (2020) Clinical Characteristics and Electrophysiological Biomarkers of Parkinson's Disease Developed

From Essential Tremor.

Front. Neurol. 11:582471

doi: 10.3389/fneur.2020.582471

\section{Clinical Characteristics and Electrophysiological Biomarkers of Parkinson's Disease Developed From Essential Tremor}

\author{
Xuemei Wang 1,2, Zhentang Cao ${ }^{1,2}$, Genliang Liu ${ }^{1,2}$, Zhu Liu ${ }^{1,2}$, Ying Jiang ${ }^{1,2}$, Huizi Ma ${ }^{1,2}$, \\ Zhan Wang ${ }^{1,2}$, Yaqin Yang ${ }^{1,2}$, Huimin Chen ${ }^{1,2}$ and Tao Feng ${ }^{1,2,3 *}$ \\ ${ }^{1}$ Center for Movement Disorders Disease, Department of Neurology, Beijing Tiantan Hospital, Capital Medical University, \\ Beijing, China, ${ }^{2}$ China National Clinical Research Center for Neurological Diseases, Beijing, China, ${ }^{3}$ Parkinson's Disease \\ Center, Beijing Institute for Brain Disorders, Beijing, China
}

Background and Objective: Parkinson's disease developed from essential tremor (ET-PD) is a distinct clinical syndrome that is different from essential tremor (ET) and Parkinson's disease (PD). There is currently a lack of research on ET-PD. Tremor characteristics (amplitude and frequency) are primary quantitative indexes for diagnosing and monitoring of tremors. In this study, we aimed to explore specific clinical and electrophysiological biomarkers for the identification of ET-PD.

Methods: The study included patients with ET-PD $(n=22)$, ET $(n=42)$, and tremor-dominant PD (t-PD, $n=47)$. We collected demographic data, clinical characteristics (including motor and non-motor symptoms), and tremor analysis. The frequency, amplitude, contracting patterns of resting tremor and postural tremor were collected. The analysis of ET-PD and ET/t-PD was compared. The receiver operating characteristic $(\mathrm{ROC})$ curve was used to analyze the electrophysiological features in distinguishing ET-PD from ET or t-PD.

Results: Compared with ET, hyposmia, bradykinesia, rigidity, postural abnormality, and resting tremor were more common in the ET-PD group $(P=0.01,0.003,0.001,0.001$, 0.019 , respectively). The postural tremor frequencies of the head, upper limbs, and lower limbs were significantly lower in the ET-PD than in the ET $(P=0.007,0.003,0.035$, respectively), which were the most appropriate variables for distinguishing ET-PD from ET (AUC: 0.775, 0.727, and 0.701, respectively). Compared with t-PD, bradykinesia, rigidity, postural abnormality (both $P<0.001$ ), and resting tremor $(P=0.024)$ were less common in the ET-PD. The postural tremor amplitudes of the head and upper limbs were significantly higher in the ET-PD than in the t-PD $(P=0.022,0.001$, respectively), which were the most appropriate variables for distinguishing ET-PD from t-PD (AUC: 0.793 and 0.716).

Conclusions: Hyposmia and electrophysiological biomarkers (postural tremor frequencies and amplitudes) help early recognition of ET-PD.

Keywords: Parkinson's disease, essential tremor, tremor, clinical, electrophysiological 


\section{INTRODUCTION}

Essential tremor (ET) and idiopathic Parkinson's disease (PD) are two of the most common movement disorders. PD's motor and non-motor features may overlap with ET, making it difficult to distinguish them based on clinical characteristics (1). For example, besides the typical resting tremor, patients with PD also often exhibit postural tremor, which is more often observed in patients with ET (2). In turn, in a population-based setting, resting tremor is a common clinical feature in patients with ET, and the prevalence can reach nearly $50 \%$ (3). ET patients have significant movement slowness compared to healthy controls, and a considerable number of ET patients have movement abnormalities similar to those observed in PD patients (4). Depression, anxiety, cognitive disorders, and family history of tremors/PD were similar in both patient groups $(5,6)$. Thus, clinical and experimental evidence indicates that there are similarities between ET and PD.

It has been reported that patients with ET seem to be about four to five times more likely to develop PD than the general population (7). ET that eventually develops into PD is called essential tremor-Parkinson's disease (ET-PD) (8). Clinically, patients with ET-PD can exhibit different types of tremor, including PD-associated resting tremor and ETassociated postural tremor. Whether ET-PD is a co-occurrence of two relatively common pathologies or if ET is a prodromal stage of PD in some patients is yet to be elucidated. Electromyographic (EMG) examination is a useful tool for tremor analysis and can characterize different tremor types according to tremor amplitude, frequency, and pattern (9). Interestingly, a recent study demonstrated that patients with ET$\mathrm{PD}$, unlike patients with tremor-dominant PD (t-PD), exhibited the synchronous pattern of resting tremor (10). However, the exact phenomenology and etiology of this finding remain unclear. Besides, due to the scarce clinical data for ET-PD, it remains unknown which clinical and tremor features can differ it from ET or t-PD. This also means that the objective factors to predict the progression of ET to PD are limited. Thus, it is difficult to obtain an accurate diagnosis of ET-PD in the early stages. Considering that electrophysiological methods can effectively characterize tremor, we systematically analyzed differences in clinical and neurophysiological features between patients with ET-PD and ET/t-PD to determine clinical and electrophysiological markers of ET-PD in order to obtain useful and targeted treatment in the early stage of ET-PD.

\section{MATERIALS AND METHODS}

\section{Patients}

From March 2018 to October 2019, patients with ET-PD $(n=22)$, ET $(n=42)$, and t-PD $(n=47)$ were recruited from Beijing Tiantan Hospital. A diagnosis of PD was made according to the Movement Disorders Society Clinical Diagnostic Criteria for Parkinson's disease in 2015 (11). The t-PD group's inclusion criteria were as follows: patients had at least one-limb resting or postural tremor, and the age of onset was $>50$ years old. Exclusion criteria for the t-PD group were as follows: (1) secondary parkinsonism; (2) atypical PD; and (3) severe heart disease, liver or kidney disease, or any other chronic disease meaning that the patient could not complete the examinations. A diagnosis of ET was made using criteria from the Movement Disorder Society Tremor Investigation Group (12). A diagnosis of ET was not assigned if bradykinesia, rigidity, or resting tremor appeared within 5 years of the onset of tremor attributed to ET.

Inclusion criteria of the ET-PD (13) group were as follows: (1) ET had been diagnosed at least 5 years before the PD diagnosis and (2) when they had received a previous diagnosis of ET, patients exhibited significant characteristics of postural tremor without any symptoms or signs of PD. Exclusion criteria for ETPD were as follows: (1) age at PD diagnosis $<40$ years old; (2) atypical PD or secondary parkinsonism; and (3) patients with a history of postural or action tremor $<5$ years.

For all patients, we collected demographic data (sex and age), clinical data including motor symptoms, non-motor symptoms, age of onset of PD, disease duration, tremor location, tremor pattern, past medical history, family history, medication history, and anti-tremor drug responsiveness. The Unified Parkinson's Disease Rating Scale (UPDRS) and the Hoehn \& Yahr (H\&Y) scale in an "off" phase ( $>12 \mathrm{~h}$ after the last dose of dopaminergic medication; $>24 \mathrm{~h}$ after anticholinergics or $\beta$-blockers) were evaluated for the t-PD and ET-PD groups (14).

This study was approved by the Ethics Committee of Beijing Tiantan Hospital and was performed in accordance with the Declaration of Helsinki. All patients provided informed consent.

\section{Definition of Non-motor Features}

Constipation was defined according to the Rome III diagnostic criteria (15).

Olfactory function was evaluated with the 12-item Sniffin' Sticks test (Burghart Messtechnik GmbH, Wedel, Germany). Patients were considered to have rapid eye movement sleep behavior disorder (RBD) when they fulfilled the criteria determined by the REM Sleep Behavior Disorder Screening Questionnaire (RBDSQ) (16).

Depression was assessed using the Hamilton Depression Rating Scale (HAMD) (17), and anxiety was assessed using the Hamilton Anxiety Rating Scale (HAMA) (18).

Cognitive status was assessed using the Mini-Mental State Examination (MMSE) scale (19) and the Montreal Cognitive Assessment (MoCA) scale (20).

\section{Tremor Analysis}

Tremor was recorded using an electromyography evoked potential meter (Nicolet EDX, USA), which has four pairs of surface electrodes and two piezoresistive accelerators. The recording electrodes were placed on the muscle bellies of the flexor carpi and extensor carpi of both forearms and lower limbs. The reference electrode was placed on the corresponding tendon, and the accelerator was fixed at the proximal end of the third metacarpal of the ipsilateral hand. For head tremor examination, the recording electrode was placed at the midpoint of the sternocleidomastoid muscle, and the reference electrode was placed in the supraclavicular fossa. The EMG parameters were as follows: amplifier sensitivity at $100 \mu \mathrm{V} / \mathrm{div}$, sweep speed at 100 
ms/div, and a filter width of $10.0 \mathrm{~Hz}-10.0 \mathrm{kHz}$; piezoresistive accelerometer sensitivity at $2.2 \mathrm{mV} / \mathrm{g}$ and a filter width in the range $0.5-30.0 \mathrm{~Hz}$.

Tremor was assessed under the following six conditions: (1) resting tremor of the head was assessed while patients sat in an armchair, leaning their head and back against the chair back, and relaxing their head; (2) resting tremor in the upper limbs was assessed while patients sat in an armchair with the forearms and hands completely rested on the armrests; (3) resting tremor in the lower limbs was assessed while patients sat in an armchair, with their feet placed flatly on the ground, and while they were utterly relaxed; (4) postural tremor in the head was assessed while patients sat in an armchair, keeping their head upright; (5) postural tremor in the upper limbs was assessed while patients sat in an armchair with wrists/fingers outstretched on a horizontal plane; and (6) postural tremor in the lower limbs was assessed while patients sat in an armchair with both sides of their toes touching the ground and with their heels hanging. Each measurement session lasted for $30 \mathrm{~s}$. The EMG data were analyzed using the TRAS system (21). All tests were performed during the patients' “off” state (22). Resting and postural tremor frequency, tremor amplitude, and systolic patterns were recorded.

\section{Statistical Analysis}

Analyses were performed using SPSS 24.0 software (SPSS Inc., Chicago, IL, USA). Graphs were delineated by using Prism 7.0 (GraphPad software, La Jolla, CA, USA). The normality of distribution of continuous variables was tested by one-sample Kolmogorov-Smirnov test. Continuous variables with normal distribution were presented as mean \pm standard deviation (SD). The differences in continuous variables between the ET-PD and ET/t-PD groups were assessed using independent samples Student's test when the data were normally distributed and using Mann-Whitney $U$ test if the data were not normally distributed. A chi-square test was used to compare categorical variables between the groups. Sensitivity and specificity for differentiating ET-PD from ET or t-PD were calculated using the optimal cutoff value determined by receiver operating characteristic (ROC) curve analysis. The optimum cutoff value for the ROC curve was determined using the Youden Index. Differences with a $P<0.05$ were considered to be statistically significant.

\section{RESULTS}

\section{Comparison of Demographic, Clinical, and Electrophysiological Features Between Patients With Essential Tremor-Parkinson's Disease and Essential Tremor \\ Differences in Demographic Variables}

The demographic data are shown in Table 1. Compared with the ET group, there was no difference in the ET-PD group regardless of sex or age.
TABLE 1 | Comparison of demographic, clinical, and electrophysiological features between patients with ET-PD and ET.

\begin{tabular}{|c|c|c|c|}
\hline Variables & ET-PD $(n=22)$ & ET $(n=42)$ & $P$-value \\
\hline \multicolumn{4}{|c|}{ Demographic characteristics } \\
\hline Age, years (mean \pm SD) & $64.14 \pm 9.26$ & $59.10 \pm 10.47$ & 0.56 \\
\hline Sex: No. men/women & $10 / 12$ & 23/19 & 0.48 \\
\hline \multicolumn{4}{|l|}{ Clinical characteristics } \\
\hline $\begin{array}{l}\text { Family history } \\
\text { (Postural/kinetic tremor), } \\
n(\%)\end{array}$ & $13(59)$ & $27(63)$ & 0.683 \\
\hline $\begin{array}{l}\text { Age at onset of ET, years } \\
\text { (mean } \pm \text { SD) }\end{array}$ & $50.86 \pm 12.11$ & $41.83 \pm 16.62$ & $0.025^{\star}$ \\
\hline $\begin{array}{l}\text { Disease duration of ET, } \\
\text { years (mean } \pm S D \text { ) }\end{array}$ & $13.27 \pm 9.99$ & $17.40 \pm 11.47$ & 0.054 \\
\hline $\begin{array}{l}\text { Disease duration from ET to } \\
\text { PD onset, years } \\
\text { (mean } \pm \text { SD) }\end{array}$ & $12.30 \pm 2.18$ & - & - \\
\hline Constipation, $n$ (\%) & $7(32)$ & $9(21)$ & 0.362 \\
\hline Hyposmia, $n(\%)$ & $6(27)$ & $2(5)$ & $0.01^{*}$ \\
\hline $\mathrm{RBD}, n(\%)$ & $8(36)$ & $7(17)$ & 0.077 \\
\hline HAMD (mean \pm SD) & $12.88 \pm 6.90$ & $9.50 \pm 7.43$ & 0.122 \\
\hline HAMA (mean \pm SD) & $13.88 \pm 4.39$ & $9.40 \pm 8.03$ & 0.114 \\
\hline MMSE (mean \pm SD) & $23.38 \pm 7.96$ & $22.80 \pm 8.77$ & 0.572 \\
\hline MoCA (mean \pm SD) & $17.50 \pm 7.71$ & $18.70 \pm 8.06$ & 0.909 \\
\hline Bradykinesia, $n$ (\%) & $10(45.50)$ & $5(12)$ & $0.003^{*}$ \\
\hline Rigidity, n (\%) & $7(32)$ & $1(2)$ & $0.001^{\star}$ \\
\hline Postural abnormality, $n$ (\%) & $7(32)$ & $1(2)$ & $0.001^{*}$ \\
\hline $\begin{array}{l}\text { Drinking responsiveness, } \\
n(\%)\end{array}$ & $5(23)$ & $18(43)$ & 0.111 \\
\hline $\begin{array}{l}\text { Arotinolol responsiveness, } \\
n(\%)\end{array}$ & $6(37.50)$ & $25(60)$ & $0.014^{\star}$ \\
\hline $\begin{array}{l}\text { Unilateral disease onset, } \\
n(\%)\end{array}$ & $13(59)$ & $13(31)$ & $0.029^{*}$ \\
\hline $\begin{array}{l}\text { Bilateral disease onset, } \\
n(\%)\end{array}$ & $9(41)$ & $29(69)$ & $0.029^{\star}$ \\
\hline Upper limb tremor, $n$ (\%) & $22(100)$ & $42(100)$ & - \\
\hline Lower limb tremor, $n$ (\%) & $15(68)$ & $9(21)$ & $<0.001^{*}$ \\
\hline Head tremor, $n$ (\%) & $10(45.50)$ & $18(43)$ & 0.842 \\
\hline Mandibular tremor, $n(\%)$ & $5(23)$ & $2(5)$ & $0.029^{\star}$ \\
\hline Resting tremor, $n$ (\%) & $16(73)$ & $20(48)$ & $0.019^{\star}$ \\
\hline Postural tremor, $n(\%)$ & $22(100)$ & $41(98)$ & 0.466 \\
\hline \multicolumn{4}{|c|}{ Electrophysiological description } \\
\hline \multicolumn{4}{|l|}{ Resting tremor } \\
\hline \multicolumn{4}{|l|}{ Frequency (Hz) } \\
\hline Head & $4.78 \pm 0.25$ & $5.92 \pm 0.98$ & 0.058 \\
\hline Upper limbs & $4.56 \pm 0.87$ & $5.33 \pm 1.20$ & 0.064 \\
\hline Lower limbs & $4.72 \pm 0.88$ & - & - \\
\hline \multicolumn{4}{|l|}{ Amplitude $(\mu \mathrm{V})$} \\
\hline Head & $352.00 \pm 98.57$ & $309.10 \pm 105.55$ & 0.525 \\
\hline Upper limbs & $1104.27 \pm 435.39$ & $689.11 \pm 313.05$ & 0.132 \\
\hline Lower limbs & $469.23 \pm 313.38$ & - & - \\
\hline \multicolumn{4}{|l|}{ Synchronous patterns, $n(\%)$} \\
\hline Head & 4/5 (80) & $5 / 5(100)$ & 0.292 \\
\hline Upper limbs & 5/16 (31) & $9 / 18(50)$ & 0.332 \\
\hline Lower limbs & $5 / 10(50)$ & 0 & - \\
\hline
\end{tabular}

(Continued) 
TABLE 1 | Continued

\begin{tabular}{|c|c|c|c|}
\hline Variables & ET-PD $(n=22)$ & ET $(n=42)$ & $P$-value \\
\hline \multicolumn{4}{|c|}{ Alternating patterns, $n$ (\%) } \\
\hline Head & $0 / 5(0)$ & $0 / 5(0)$ & - \\
\hline Upper limbs & $8 / 16(50)$ & 8/18 (44) & 0.877 \\
\hline Lower limbs & $3 / 10(30)$ & 0 & - \\
\hline \multicolumn{4}{|c|}{ Synchronous and alternating patterns, $n$ (\%) } \\
\hline Head & $1 / 5(20)$ & $0 / 5(0)$ & 0.292 \\
\hline Upper limbs & $3 / 16(19)$ & $1 / 18(6)$ & 0.212 \\
\hline Lower limbs & $2 / 10(20)$ & 0 & - \\
\hline \multicolumn{4}{|l|}{ Postural tremor } \\
\hline \multicolumn{4}{|l|}{ Frequency $(\mathrm{Hz})$} \\
\hline Head & $4.50 \pm 0.45$ & $5.41 \pm 1.01$ & $0.007^{*}$ \\
\hline Upper limbs & $5.15 \pm 1.04$ & $6.13 \pm 1.49$ & $0.003^{*}$ \\
\hline Lower limbs & $5.10 \pm 1.37$ & $6.35 \pm 0.91$ & $0.035^{*}$ \\
\hline \multicolumn{4}{|l|}{ Amplitude $(\mu \mathrm{V})$} \\
\hline Head & $474.07 \pm 166.99$ & $661.97 \pm 242.99$ & 0.738 \\
\hline Upper limbs & $1,419.70 \pm 426.17$ & $922.91 \pm 135.29$ & 0.364 \\
\hline Lower limbs & $1,039.23 \pm 221.46$ & $504.96 \pm 263.43$ & 0.132 \\
\hline \multicolumn{4}{|c|}{ Synchronous patterns, $n(\%)$} \\
\hline Head & $5 / 7(71)$ & 14/16 (87.50) & 0.499 \\
\hline Upper limbs & 4/22 (18) & $22 / 40(55)$ & $0.005^{\star}$ \\
\hline Lower limbs & 8/11 (73) & $3 / 3(100)$ & 0.308 \\
\hline \multicolumn{4}{|c|}{ Alternating patterns, $n$ (\%) } \\
\hline Head & $0 / 7(0)$ & $1 / 16(6.25)$ & 0.349 \\
\hline Upper limbs & $10 / 22(46)$ & $9 / 40(22.50)$ & 0.061 \\
\hline Lower limbs & 1/11 (9) & $0 / 3(0)$ & 0.588 \\
\hline \multicolumn{4}{|c|}{ Synchronous and alternating patterns, $n(\%)$} \\
\hline Head & 2/7 (29) & $1 / 16(6.25)$ & 0.144 \\
\hline Upper limbs & 8/22 (36) & $9 / 40(22.50)$ & 0.242 \\
\hline Lower limbs & 2/11 (18) & 0/3 (0) & 0.425 \\
\hline
\end{tabular}

$E T-P D$, Parkinson's disease developed from essential tremor; $E T$, essential tremor; $R B D$, rapid eye movement sleep behavioral disorder; HAMD, Hamilton Depression Scale; HAMA, Hamilton Anxiety Rating Scale; MMSE, Mini-Mental State Examination; MoCA, Montreal Cognitive Assessment; UPDRS, Unified Parkinson's Disease Rating Scale.

*This $P$-value indicates a statistically significant difference.

\section{Differences in Clinical Characteristics}

All clinical data are shown in Table 1. The ET-PD group had an older mean age at onset of ET than the ET group $(P=0.025)$. The average latency of ET to PD diagnosis in the ET-PD group was $12.30 \pm 2.18$ years. Hyposmia was significantly more common in the ET-PD group than the ET group $(P=0.01)$, but no other significant differences in non-motor features were found between these two groups. Concerning motor features, the proportion of patients with ET-PD with asymmetric motor symptoms (59\%) was higher than that in the ET group $(P=0.029)$. Bradykinesia, rigidity, and postural abnormalities were more common in the ET-PD group than the ET group $(P=0.003,0.001,0.001$, respectively). Resting tremor was found in $73 \%$ of the ET-PD group, which was a significantly higher proportion than that in the ET group $(P=0.019)$. Lower limb tremor was significantly more common in the ET-PD group than that in the ET group ( $P$ $<0.001)$, as was mandibular tremor $(P=0.029)$.

\section{Difference in Electrophysiological Results}

Postural tremor was observed in almost all patients in the ET$\mathrm{PD}$ and ET groups. However, the postural tremor frequency differed between the ET-PD and ET groups. The postural tremor frequencies of the head, upper limbs, and lower limbs were significantly lower in the ET-PD group than those in the ET group ( $P=0.007,0.003,0.035$, respectively; Table 1$)$. The cutoff value of head postural tremor frequency to distinguish patients with ET-PD from ET was $5.20 \mathrm{~Hz}$, with a sensitivity of $67 \%$ and specificity of $100 \%$. The cutoff value of postural tremor frequency to distinguish patients with ET-PD from ET was $5.45 \mathrm{~Hz}$ for the upper limbs and $5.98 \mathrm{~Hz}$ for the lower limbs, with a sensitivity of $100 \%$ and specificity of $83 \%$, respectively (Table 3, Figure 1A). Furthermore, upper limb postural tremor patterns were less synchronous in the ET-PD group than those in the ET group (Table 1).

\section{Comparison of Demographic, Clinical, and Electrophysiological Features Between Patients With Essential Tremor-Parkinson's Disease and Tremor-Dominant Parkinson's Disease Differences in Demographic Variables}

The demographic data are shown in Table 2. Compared with the $\mathrm{t}-\mathrm{PD}$ group, there was no difference in the ET-PD group regardless of sex or age.

\section{Differences in Clinical Characteristics}

All clinical data are shown in Table 2. The ET-PD group had an older mean age at onset of PD than the t-PD group $(P=0.004)$. Some non-motor features were significantly less common in the ET-PD group than the t-PD group, including constipation $(P<$ $0.001)$, hyposmia $(P=0.044)$, and $\operatorname{RBD}(P=0.033)$. The HAMD, HAMA, MMSE, and MoCA scores did not differ between the two groups. Concerning motor features, the proportion of patients with ET-PD with asymmetric motor symptoms was lower than that in the $\mathrm{t}-\mathrm{PD}$ group $(P<0.001)$. Bradykinesia, rigidity, and postural abnormalities were less common in the ET-PD group than the t-PD group (both $P<0.001$ ). Resting tremor was found in $73 \%$ of the ET-PD group, which was lower than that in the t-PD group $(P=0.024)$. Head tremor was more common in the ET-PD group than the $\mathrm{t}-\mathrm{PD}$ group $(P<0.001)$. Mandibular tremor was less common in the ET-PD group than the $\mathrm{t}-\mathrm{PD}$ group $(P=0.038)$.

\section{Difference in Electrophysiological Results}

The head and upper limbs' postural tremor amplitudes were significantly higher in the ET-PD group than those in the t-PD group ( $P=0.022,0.001$, respectively; Table 2 ). To distinguish patients with ET-PD from t-PD, the cutoff value of head postural tremor amplitude was $477.50 \mu \mathrm{V}$, with a sensitivity of $57 \%$ and specificity of $90 \%$. For the upper limbs, the postural tremor amplitude cutoff value was $393.00 \mu \mathrm{V}$, with a sensitivity of $86 \%$ and specificity of $60 \%$ (Table 3, Figure 1B). 


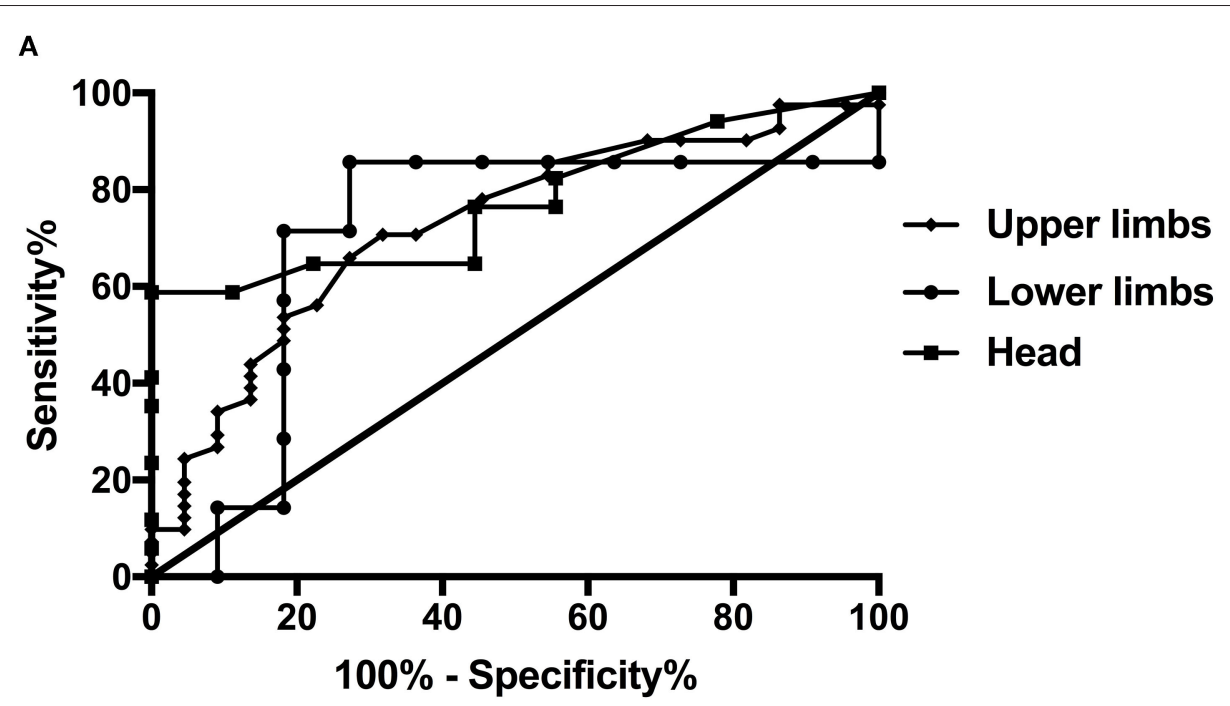

B

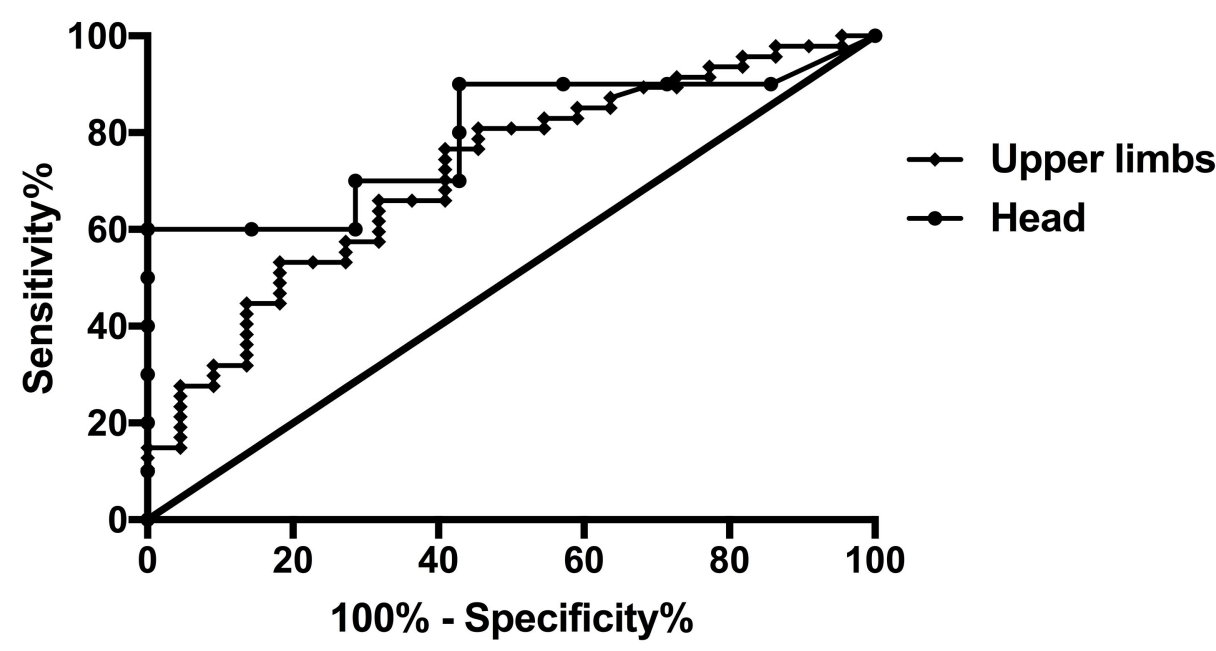

FIGURE 1 | Receiver operating characteristic (ROC) curve differentiating essential tremor-Parkinson's disease (ET-PD) from essential tremor (ET) or tremor-dominant Parkinson's disease (t-PD). (A) ROC curve of postural tremor frequency to differentiate ET-PD from ET. (B) ROC curve of postural tremor amplitude to differentiate ET-PD from t-PD.

\section{DISCUSSION}

ET-PD and ET/t-PD can be clinically difficult to differentiate because of overlapping motor and non-motor symptoms. This study showed that hyposmia and electrophysiological biomarkers (postural tremor frequencies and amplitudes) could distinguish patients with ET-PD from those with ET or t-PD.

Epidemiological and clinical evidence has supported the view that the lifetime risk of developing $\mathrm{PD}$ was higher in patients with ET than those without ET (23). A long latency could be up to 50 years (24). Like previous studies $(6,25)$, we found that the average latency for ET patients to develop PD was $12.30 \pm 2.18$ years. Furthermore, in the ET-PD group, the age of onset of ET tended to be older than that in the ET group, while the age of onset of PD was older than that in the t-PD group. There was no significant difference between the ET-PD and ET groups concerning sex, which is in accordance with a previous study (25) but conflicts with another study that reported a male predominance of ETPD (26). It may need a further prospective study to explore the epidemiological characteristics of ET-PD.

In our cohort, the HAMD, HAMA, MMSE, and MoCA scores did not differ between ET-PD and ET/t-PD. However, constipation, hyposmia, and RBD were more common in the t-PD group than the ET-PD group, while hyposmia, rather than constipation or RBD, was more common in the ET-PD group than the ET group, which was consistent with previous studies $(5,25)$. Another study found no significant differences between patients with ET-PD and ET with regard to non-motor features (10). These conflicting results may be due to different mean durations of ET development into PD and/or the different 
TABLE 2 | Comparison of demographic, clinical, and electrophysiological features between patients with ET-PD and t-PD.

\begin{tabular}{|c|c|c|c|}
\hline Variables & ET-PD $(n=22)$ & t-PD $(n=47)$ & $P$-value \\
\hline \multicolumn{4}{|c|}{ Demographic characteristics } \\
\hline Age, years (mean $\pm S D$ ) & $64.14 \pm 9.26$ & $63.28 \pm 7.01$ & 0.07 \\
\hline Sex: No. men/women & $10 / 12$ & $24 / 23$ & 0.67 \\
\hline \multicolumn{4}{|l|}{ Clinical characteristics } \\
\hline $\begin{array}{l}\text { Family history } \\
\text { (Postural/kinetic tremor), } \\
n \text { (\%) }\end{array}$ & $13(59)$ & $9(19)$ & $0.001^{*}$ \\
\hline $\begin{array}{l}\text { Age at onset of PD, years } \\
\text { (mean } \pm \text { SD) }\end{array}$ & $63.16 \pm 9.62$ & $56.51 \pm 8.05$ & $0.004^{*}$ \\
\hline $\begin{array}{l}\text { Disease duration, years } \\
\text { (mean } \pm \mathrm{SD} \text { ) }\end{array}$ & $13.27 \pm 9.99$ & $6.83 \pm 4.53$ & $0.008^{*}$ \\
\hline Constipation, $n(\%)$ & $7(32)$ & $39(83)$ & $<0.001^{*}$ \\
\hline Hyposmia, $n$ (\%) & $6(27)$ & $25(53)$ & $0.044^{*}$ \\
\hline $\mathrm{RBD}, n(\%)$ & $8(36)$ & $30(64)$ & $0.033^{*}$ \\
\hline HAMD (mean \pm SD) & $12.88 \pm 6.90$ & $11.13 \pm 9.02$ & 0.774 \\
\hline HAMA (mean \pm SD) & $13.88 \pm 4.39$ & $12.84 \pm 7.34$ & 0.920 \\
\hline MMSE (mean \pm SD) & $23.38 \pm 7.96$ & $26.00 \pm 3.09$ & 0.777 \\
\hline MoCA (mean \pm SD) & $17.50 \pm 7.71$ & $22.19 \pm 4.71$ & 0.168 \\
\hline Bradykinesia, $n$ (\%) & $10(45.50)$ & $47(100)$ & $<0.001^{*}$ \\
\hline Rigidity, $n$ (\%) & $7(32)$ & $43(91.5)$ & $<0.001^{*}$ \\
\hline Postural abnormality, $n$ (\%) & $7(32)$ & $45(96)$ & $<0.001^{*}$ \\
\hline UPDRS part 3 (mean \pm SD) & $31.00 \pm 1.41$ & $38.39 \pm 17.71$ & 0.661 \\
\hline Hoehn-Yahr (mean \pm SD) & $2.41 \pm 0.42$ & $2.75 \pm 0.85$ & 0.054 \\
\hline $\begin{array}{l}\text { Dopaminergic } \\
\text { responsiveness, } n \text { (\%) }\end{array}$ & $7(32)$ & $30(64)$ & $0.013^{*}$ \\
\hline $\begin{array}{l}\text { Unilateral disease onset, } \\
n(\%)\end{array}$ & $13(59)$ & $47(100)$ & $<0.001^{*}$ \\
\hline $\begin{array}{l}\text { Bilateral disease onset, } \\
n(\%)\end{array}$ & $9(41)$ & $0(0)$ & $<0.001^{*}$ \\
\hline Upper limb tremor, $n$ (\%) & $22(100)$ & $44(94)$ & 0.226 \\
\hline Lower limb tremor, $n$ (\%) & $15(68)$ & $27(57)$ & 0.593 \\
\hline Head tremor, $n(\%)$ & $10(45.50)$ & $3(6)$ & $<0.001^{*}$ \\
\hline Mandibular tremor, $n(\%)$ & $5(23)$ & $22(47)$ & $0.038^{\star}$ \\
\hline Resting tremor, $n(\%)$ & $16(73)$ & $42(89)$ & $0.024^{\star}$ \\
\hline Postural tremor, $n$ (\%) & $22(100)$ & $47(100)$ & - \\
\hline \multicolumn{4}{|c|}{ Electrophysiological description } \\
\hline \multicolumn{4}{|l|}{ Resting tremor } \\
\hline \multicolumn{4}{|l|}{ Frequency $(\mathrm{Hz})$} \\
\hline Head & $4.78 \pm 0.25$ & $4.63 \pm 0.56$ & 0.887 \\
\hline Upper limbs & $4.56 \pm 0.87$ & $4.47 \pm 0.60$ & 0.947 \\
\hline Lower limbs & $4.72 \pm 0.88$ & $4.21 \pm 0.55$ & 0.336 \\
\hline \multicolumn{4}{|l|}{ Amplitude $(\mu \mathrm{V})$} \\
\hline Head & $352.00 \pm 98.57$ & $318.56 \pm 184.14$ & 0.646 \\
\hline Upper limbs & $1,104.27 \pm 435.39$ & $703.53 \pm 112.51$ & 0.464 \\
\hline Lower limbs & $469.23 \pm 313.38$ & $426.22 \pm 74.97$ & 0.776 \\
\hline \multicolumn{4}{|l|}{ Synchronous patterns, $n(\%)$} \\
\hline Head & $4 / 5(80)$ & $5 / 9(56)$ & 0.360 \\
\hline Upper limbs & $5 / 16(31)$ & 6/37 (16) & 0.215 \\
\hline Lower limbs & 5/10 (50) & $10(48)$ & 0.595 \\
\hline \multicolumn{4}{|l|}{ Alternating patterns, $n(\%)$} \\
\hline Head & $0 / 5(0)$ & 1/9 (11) & 0.439 \\
\hline
\end{tabular}

(Continued)
TABLE 2 | Continued

\begin{tabular}{|c|c|c|c|}
\hline Variables & ET-PD $(n=22)$ & t-PD $(n=47)$ & $P$-value \\
\hline Upper limbs & $8 / 16(50)$ & 23/37 (62) & 0.409 \\
\hline Lower limbs & 3/10 (30) & $7(33)$ & 0.560 \\
\hline \multicolumn{4}{|c|}{ Synchronous and alternating patterns, $n(\%)$} \\
\hline Head & $1 / 5(20)$ & 3/9 (33) & 0.597 \\
\hline Upper limbs & $3 / 16$ (19) & 8/37 (22) & 0.813 \\
\hline Lower limbs & 2/10 (20) & $4(19)$ & 0.950 \\
\hline \multicolumn{4}{|l|}{ Postural tremor } \\
\hline \multicolumn{4}{|l|}{ Frequency $(\mathrm{Hz})$} \\
\hline Head & $4.50 \pm 0.45$ & $4.40 \pm 0.79$ & 0.850 \\
\hline Upper limbs & $5.15 \pm 1.04$ & $4.96 \pm 0.70$ & 0.948 \\
\hline Lower limbs & $5.10 \pm 1.37$ & $4.84 \pm 0.79$ & 0.924 \\
\hline \multicolumn{4}{|l|}{ Amplitude $(\mu \mathrm{V})$} \\
\hline Head & $474.07 \pm 166.99$ & $293.35 \pm 174.01$ & $0.022^{*}$ \\
\hline Upper limbs & $1,419.70 \pm 426.17$ & $787.48 \pm 197.85$ & $0.001^{*}$ \\
\hline Lower limbs & $1,039.23 \pm 221.46$ & $740.85 \pm 126.07$ & 0.157 \\
\hline \multicolumn{4}{|c|}{ Synchronous patterns, $n$ (\%) } \\
\hline Head & 5/7 (71) & 10/11 (91) & 0.280 \\
\hline Upper limbs & 4/22 (18) & $16 / 42(38)$ & 0.103 \\
\hline Lower limbs & 8/11 (73) & 18/31 (58) & 0.390 \\
\hline \multicolumn{4}{|c|}{ Alternating patterns, $n$ (\%) } \\
\hline Head & $0 / 7(0)$ & 0/11 (0) & - \\
\hline Upper limbs & $10 / 22(46)$ & $12 / 42(29)$ & 0.177 \\
\hline Lower limbs & $1 / 11(9)$ & $5 / 31(16)$ & 0.567 \\
\hline \multicolumn{4}{|c|}{ Synchronous and alternating patterns, $n(\%)$} \\
\hline Head & 2/7 (29) & 1/11 (9) & 0.280 \\
\hline Upper limbs & 8/22 (36) & $14 / 42(33)$ & 0.808 \\
\hline Lower limbs & 2/11 (18) & 8/31 (26) & 0.610 \\
\hline
\end{tabular}

$\overline{E T-P D, \text { Parkinson's disease developed from essential tremor; } t-P D \text {, tremor-dominant }}$ Parkinson's disease; RBD, rapid eye movement sleep behavioral disorder; HAMD, Hamilton Depression Scale; HAMA, Hamilton Anxiety Rating Scale; MMSE, Mini-Mental State Examination; MoCA, Montreal Cognitive Assessment; UPDRS, Unified Parkinson's Disease Rating Scale.

*This $P$-value indicates a statistically significant difference.

methodologies used in each study. In our study, early non-motor features, especially the appearance of hyposmia, may indicate that ET is beginning to develop into ET-PD. Hyposmia may be an early symptom of ET-PD/PD and is associated with cellular damage in the olfactory bulb (27).

Among the motor features, we found that bradykinesia, rigidity, and postural abnormality were more common in patients with ET-PD than ET. Bradykinesia is the cardinal motor symptom in PD, which has also been reported in ET $(4,28)$. Several studies have shown that cerebellar dysfunction is involved in the pathophysiology of movement slowness in ET $(4,29)$. As in ET, the cerebellum is thought to be involved in the pathophysiology of bradykinesia in ET-PD, which is now considered a network disorder (30). Together with basal ganglia-cortical loops, the cerebellum may be involved in the execution of repetitive movements, which play a role in movement feedback and compensate for impaired basal ganglia function (30). Moreover, bradykinesia, rigidity, and postural abnormalities are all related to the parkinsonism, resulting from 
TABLE 3 | Sensitivity, specificity, and AUC of electrophysiological features in distinguishing ET-PD patients from ET and t-PD patients.

\begin{tabular}{lccccc}
\hline Groups & Cutoff & Sensitivity & Specificity & AUC & P-value \\
\hline $\begin{array}{l}\text { ET-PD vs. ET } \\
\text { Postural tremor frequency }\end{array}$ & & & & \\
Head & 5.20 & $67 \%$ & $100 \%$ & 0.775 & 0.023 \\
Upper limbs & 5.45 & $100 \%$ & $83 \%$ & 0.727 & 0.003 \\
Lower limbs & 5.98 & $100 \%$ & $83 \%$ & 0.701 & 0.160 \\
$\begin{array}{l}\text { ET-PD vs. t-PD } \\
\text { Postural tremor amplitude }\end{array}$ & & & & \\
Head & 477.50 & $57 \%$ & $90 \%$ & 0.793 & 0.040 \\
Upper limbs & 393.00 & $86 \%$ & $60 \%$ & 0.716 & 0.004 \\
\hline
\end{tabular}

ET-PD, Parkinson's disease developed from essential tremor; $t-P D$, tremor-dominant Parkinson's disease; ET, essential tremor.

decreased dopaminergic transmission in the motor region of the striatum, involving connectivity of the globus pallidus to the cortico-basal ganglia-cerebello motor circuit (31). Several recent clinicopathological studies suggested that the dramatic loss of these dopaminergic neurons starts before the onset of motor symptoms (32). Maybe the appearance of motor features in patients with ET-PD is also related to the change in their dopamine levels and could be an early symptom of the conversion from ET to ET-PD.

EMG examination is a convenient and inexpensive tool to discriminate patients with ET-PD from ET/t-PD (33) compared with the magnetic resonance support vector machine (34). In accordance with previous studies $(8,26)$, resting tremor was significantly more common in the ET-PD group than the ET group in our study. Recent studies observed higher connectivity of the globus pallidus pars interna (GPi) and putamen to the cerebello-thalamic circuit (35) and an impairment of the basal ganglia-thalamocortical loop $(36,37)$. Another study showed that the globus pallidus, caudate nucleus, and supplementary motor area were specifically damaged in ET patients with resting tremor (38). These works suggested that dopaminergic loss in the pallidum might induce hyperactivity in the cerebello-thalamic circuit, leading to resting tremor. Since it was found that a subset of patients with ET eventually developed PD (5), we hypothesized that resting tremor may be a prominent feature of early-stage ET$\mathrm{PD}$, which may involve similar pathological loops as those in t-PD patients (10).

Besides resting tremor, we also observed that postural tremor frequencies of the head, upper limbs, and lower limbs were significantly lower in patients with ET-PD than those with ET. Furthermore, the head and upper limbs' postural tremor amplitudes were significantly higher in patients with ET-PD than those with t-PD. The cutoff values to distinguish patients with ET-PD from those with ET/t-PD have high sensitivity and specificity. Indeed, the exact central oscillators in the genesis of postural tremor in ET-PD are not fully understood. Some studies have concluded that postural tremor is triggered by the basal ganglia $(39,40)$ and mediated by the cerebello-thalamiccortical network $(41,42)$. Tremor amplitude and frequency are primary quantitative indexes for diagnosing and monitoring of tremors. There is evidence that the tremor frequency decreases with time, which could be an essential factor leading to a deterioration of ET (43). Another study showed that patient's conditions directly affect neural oscillations related to tremor frequencies (44). Central oscillators control tremor frequency while peripheral nerves and muscles exert a modulatory influence on tremor amplitude. The reduction of tremor amplitude is accompanied by increased variability of tremor frequency due to the desynchronization of central oscillators (39). We observed that the postural tremor amplitudes were higher in the ET$\mathrm{PD}$ group than those in the t-PD group, and that the postural tremor frequencies were lower in the ET-PD group than those in the ET group. We try to explain this phenomenon as a consequence of increasing the number of active central oscillators and an increased synchronization of central oscillators in the ET-PD group.

To our knowledge, very few studies were conducted to explore the quantitative electrophysiological biomarkers for ET$\mathrm{PD}$ at present. Furthermore, this is also the highlight of our research. This study may be the first research about the clinical and electrophysiological characteristics of ET-PD and ET/t$\mathrm{PD}$ in Chinese populations. However, our research also has some limitations. For example, the sample size of this study is small, and the definite diagnosis of these patients was not confirmed by the pathological results. Nonetheless, all patients were carefully evaluated by professional movement specialists during hospitalization.

\section{CONCLUSION}

In the current study, we present the clinical characteristics to distinguish patients with ET-PD from those with ET, including the early appearance of hyposmia and motor symptoms. Our findings indicate that quantitative electrophysiological biomarkers, including a distinct frequency and amplitude of postural tremor, could be useful for the earlier recognition of ET-PD and beneficial to further patient treatment.

\section{DATA AVAILABILITY STATEMENT}

The raw data supporting the conclusions of this article will be made available by the authors, without undue reservation.

\section{ETHICS STATEMENT}

The studies involving human participants were reviewed and approved by the Ethics Committee of Beijing Tiantan Hospital. The patients/participants provided their written informed consent to participate in this study.

\section{AUTHOR CONTRIBUTIONS}

All authors listed have made a substantial, direct and intellectual contribution to the work, and approved it for publication. 


\section{FUNDING}

This work was supported by the National Key R\&D Program of China (Nos. 2016YFC1306501 and

\section{REFERENCES}

1. Thenganatt MA, Jankovic J. The relationship between essential tremor and Parkinson's disease. Parkinsonism Relat Disord. (2016) 22(Suppl. 1):S162-5. doi: 10.1016/j.parkreldis.2015.09.032

2. Gigante AF, Bruno G, Iliceto G, Guido M, Liuzzi D, Mancino PV, et al. Action tremor in Parkinson's disease: frequency and relationship to motor and non-motor signs. Eur J Neurol. (2015) 22:223-8. doi: 10.1111/ene.12583

3. Louis ED, Hernandez N, Michalec M. Prevalence and correlates of rest tremor in essential tremor: cross-sectional survey of 831 patients across four distinct cohorts. Eur J Neurol. (2015) 22:927-32. doi: 10.1111/ene.12683

4. Bologna M, Paparella G, Colella D, Cannavacciuolo A, Angelini L, AlunniFegatelli D, et al. Is there evidence of bradykinesia in essential tremor? Eur J Neurol. (2020) 27:1501-9. doi: 10.1111/ene.14312

5. Lau HL, Marmol SE, Margolesky J. Features in essential tremor and the development of Parkinson's disease vs. parkinsonism. Neurol Sci. (2020). doi: 10.1007/s10072-020-04439-w. [Epub ahead of print].

6. Tarakad A, Jankovic J. Essential tremor and Parkinson's disease: exploring the relationship. Tremor Other Hyperkinet Mov (N Y). (2018) 8:589. doi: 10.7916/d8md0gvr

7. Benito-Leon J, Louis ED, Bermejo-Pareja F. Risk of incident Parkinson's disease and parkinsonism in essential tremor: a population based study. $J$ Neurol Neurosurg Psychiatry. (2009) 80:423-5. doi: 10.1136/jnnp.2008.147223

8. Shahed J, Jankovic J. Exploring the relationship between essential tremor and Parkinson's disease. Parkinsonism Relat Disord. (2007) 13:67-76. doi: 10.1016/j.parkreldis.2006.05.033

9. Cohen O, Pullman S, Jurewicz E, Watner D, Louis ED. Rest tremor in patients with essential tremor: prevalence, clinical correlates, and electrophysiologic characteristics. Arch Neurol. (2003) 60:405-10. doi: 10.1001/archneur.60.3.405

10. Arabia G, Lupo A, Manfredini LI, Vescio B, Nistico R, Barbagallo G, et al. Clinical, electrophysiological, and imaging study in essential tremorParkinson's disease syndrome. Parkinsonism Relat Disord. (2018) 56:20-6. doi: 10.1016/j.parkreldis.2018.06.005

11. Postuma RB, Berg D, Stern M, Poewe W, Olanow CW, Oertel W, et al. MDS clinical diagnostic criteria for Parkinson's disease. Mov Disord. (2015) 30:1591-601. doi: 10.1002/mds.26424

12. Deuschl G, Bain P, Brin M. Consensus statement of the Movement Disorder Society on Tremor. Ad Hoc Scientific Committee. Mov Disord. (1998) 13(Suppl. 3):2-23. doi: 10.1002/mds.870131303

13. Louis ED, Wise A, Alcalay RN, Rao AK, Factor-Litvak P. Essential tremorParkinson's disease: a double whammy. J Neurol Sci. (2016) 366:47-51. doi: 10.1016/j.jns.2016.04.040

14. Noffs G, de Campos Duprat A, Zarzur AP, Cury RG, Cataldo BO, Fonoff E. Effect of Levodopa + carbidopa on the laryngeal electromyographic pattern in Parkinson disease. J Voice. (2017) 31:383.e319-83.e323. doi: 10.1016/j.jvoice.2016.09.001

15. Longstreth GF, Thompson WG, Chey WD, Houghton LA, Mearin F, Spiller RC. Functional bowel disorders. Gastroenterology. (2006) 130:1480-91. doi: 10.1053/j.gastro.2005.11.061

16. Marelli S, Rancoita PM, Giarrusso F, Galbiati A, Zucconi M, Oldani A, et al. National validation and proposed revision of REM sleep behavior disorder screening questionnaire (RBDSQ). J Neurol. (2016) 263:2470-5. doi: $10.1007 / \mathrm{s} 00415-016-8285-y$

17. Williams JB. Standardizing the Hamilton Depression Rating Scale: past, present, and future. Eur Arch Psychiatry Clin Neurosci. (2001) 251(Suppl. 2):II6-12. doi: 10.1007/BF03035120

18. Hamilton M. The assessment of anxiety states by rating. Br J Med Psychol. (1959) 32:50-5. doi: 10.1111/j.2044-8341.1959.tb00467.x

19. Folstein MF, Folstein SE, McHugh PR. "Mini-mental state." A practical method for grading the cognitive state of patients for the
2018YFC1312001), National Natural Science Foundation of China (No. 81771367), and Beijing Municipal Science \& Technology Commission (Z151100003915150 and Z171100001017041).

clinician. J Psychiatr Res. (1975) 12:189-98. doi: 10.1016/0022-3956(75) 90026-6

20. Nasreddine ZS, Phillips NA, Bedirian V, Charbonneau S, Whitehead V, Collin I, et al. The Montreal Cognitive Assessment, MoCA: a brief screening tool for mild cognitive impairment. J Am Geriatr Soc. (2005) 53:695-9. doi: 10.1111/j.1532-5415.2005.53221.x

21. Lauk M, Timmer J, Lucking CH, Honerkamp J, Deuschl G. A software for recording and analysis of human tremor. Comput Methods Programs Biomed. (1999) 60:65-77. doi: 10.1016/s0169-2607(99)00012-7

22. Chou KL, Stacy M, Simuni T, Miyasaki J, Oertel WH, Sethi K, et al. The spectrum of "off" in Parkinson's disease: what have we learned over 40 years? Parkinsonism Relat Disord. (2018) 51:9-16. doi: 10.1016/j.parkreldis.2018.02.001

23. LaRoia $\mathrm{H}$, Louis ED. Association between essential tremor and other neurodegenerative diseases: what is the epidemiological evidence? Neuroepidemiology. (2011) 37:1-10. doi: 10.1159/000328866

24. Chaudhuri KR, Buxton-Thomas M, Dhawan V, Peng R, Meilak C, Brooks DJ. Long duration asymmetrical postural tremor is likely to predict development of Parkinson's disease and not essential tremor: clinical follow up study of 13 cases. J Neurol Neurosurg Psychiatry. (2005) 76:115-7. doi: 10.1136/jnnp.2004.046292

25. Ghika A, Kyrozis A, Potagas C, Louis ED. Motor and non-motor features: differences between patients with isolated essential tremor and patients with both essential tremor and Parkinson's disease. Tremor Other Hyperkinet Mov (N Y). (2015) 5:335. doi: 10.7916/d83777wk

26. Minen MT, Louis ED. Emergence of Parkinson's disease in essential tremor: a study of the clinical correlates in 53 patients. Mov Disord. (2008) 23:1602-5. doi: $10.1002 / \mathrm{mds} .22161$

27. Hawkes CH, Shephard BC, Daniel SE. Is Parkinson's disease a primary olfactory disorder? QJM. (1999) 92:473-80. doi: 10.1093/qjmed/ 92.8.473

28. Goubault E, Nguyen HP, Ayachi FS, Bogard S, Duval C. Do bradykinesia and tremor interfere in voluntary movement of essential tremor patients? Preliminary findings. Tremor Other Hyperkinet Mov (N Y). (2017) 7:459. doi: $10.7916 / \mathrm{d} 822319 \mathrm{x}$

29. Haubenberger D, Hallett M. Essential tremor. N Engl J Med. (2018) 379:596-7. doi: 10.1056/NEJMc1807690

30. Bologna M, Paparella G, Fasano A, Hallett M, Berardelli A. Evolving concepts on bradykinesia. Brain. (2020) 143:727-50. doi: 10.1093/brain/awz344

31. Barbagallo G, Caligiuri ME, Arabia G, Cherubini A, Lupo A, Nistico R, et al. Structural connectivity differences in motor network between tremordominant and nontremor Parkinson's disease. Hum Brain Mapp. (2017) 38:4716-29. doi: 10.1002/hbm.23697

32. Poewe W, Seppi K, Tanner CM, Halliday GM, Brundin P, Volkmann J, et al. Parkinson disease. Nat Rev Dis Primers. (2017) 3:17013. doi: $10.1038 /$ nrdp. 2017.13

33. Nisticò R, Pirritano D, Novellino F, Salsone M, Morelli M, Valentino $\mathrm{P}$, et al. Blink reflex recovery cycle in patients with essential tremor associated with resting tremor. Neurology. (2012) 79:1490-5. doi: 10.1212/WNL.0b013e31826d5f83

34. Cherubini A, Nisticó R, Novellino F, Salsone M, Nigro S, Donzuso G, et al. Magnetic resonance support vector machine discriminates essential tremor with rest tremor from tremor-dominant Parkinson disease. Mov Disord. (2014) 29:1216-9. doi: 10.1002/mds.25869

35. Helmich RC, Janssen MJ, Oyen WJ, Bloem BR, Toni I. Pallidal dysfunction drives a cerebellothalamic circuit into Parkinson tremor. Ann Neurol. (2011) 69:269-81. doi: 10.1002/ana.22361

36. Pan PL, Song W, Shang HF. Voxel-wise meta-analysis of gray matter abnormalities in idiopathic Parkinson's disease. Eur J Neurol. (2012) 19:199206. doi: 10.1111/j.1468-1331.2011.03474.x 
37. Stoessl AJ, Martin WW, McKeown MJ, Sossi V. Advances in imaging in Parkinson's disease. Lancet Neurol. (2011) 10:987-1001. doi: 10.1016/s1474-4422(11)70214-9

38. Caligiuri ME, Arabia G, Barbagallo G, Lupo A, Morelli M, Nistico R, et al. Structural connectivity differences in essential tremor with and without resting tremor. J Neurol. (2017) 264:1865-74. doi: 10.1007/s00415-017-8553-5

39. Bartolic A, Pirtosek Z, Rozman J, Ribaric S. Tremor amplitude and tremor frequency variability in Parkinson's disease is dependent on activity and synchronisation of central oscillators in basal ganglia. Med Hypotheses. (2010) 74:362-5. doi: 10.1016/j.mehy.2009.06.057

40. Du G, Zhuang P, Hallett M, Zhang YQ, Li JY, Li YJ. Properties of oscillatory neuronal activity in the basal ganglia and thalamus in patients with Parkinson's disease. Transl Neurodegener. (2018) 7:17. doi: 10.1186/s40035-018-0123-y

41. Pinto AD, Lang AE, Chen R. The cerebellothalamocortical pathway in essential tremor. Neurology. (2003) 60:1985-7. doi: 10.1212/01.wnl.0000065890.75790.29

42. Cerasa A, Novellino F, Quattrone A. Connectivity changes in Parkinson's disease. Curr Neurol Neurosci Rep. (2016) 16:91. doi: 10.1007/s11910-016-0687-9
43. Hellwig B, Mund P, Schelter B, Guschlbauer B, Timmer J, Lücking $\mathrm{CH}$. A longitudinal study of tremor frequencies in Parkinson's disease and essential tremor. Clin Neurophysiol. (2009) 120:431-5. doi: 10.1016/j.clinph.2008.11.002

44. Lee HJ, Lee WW, Kim SK, Park H, Jeon HS, Kim HB, et al. Tremor frequency characteristics in Parkinson's disease under resting-state and stressstate conditions. J Neurol Sci. (2016) 362:272-7. doi: 10.1016/j.jns.2016. 01.058

Conflict of Interest: The authors declare that the research was conducted in the absence of any commercial or financial relationships that could be construed as a potential conflict of interest.

Copyright (c) 2020 Wang, Cao, Liu, Liu, Jiang, Ma, Wang, Yang, Chen and Feng. This is an open-access article distributed under the terms of the Creative Commons Attribution License (CC BY). The use, distribution or reproduction in other forums is permitted, provided the original author(s) and the copyright owner(s) are credited and that the original publication in this journal is cited, in accordance with accepted academic practice. No use, distribution or reproduction is permitted which does not comply with these terms. 